\title{
Fate of centrosomes following somatic cell nuclear transfer (SCNT) in bovine oocytes
}

\author{
Yunping Dai ${ }^{1}$, Lili Wang ${ }^{1}$, Haiping Wang ${ }^{1}$, Ying Liu ${ }^{1}$, Ning Li ${ }^{1}$, Qifeng Lyu ${ }^{2}$, David L Keefe ${ }^{3}$, \\ David F Albertini ${ }^{4}$ and Lin Liu ${ }^{2,3}$ \\ ${ }^{1}$ State Key Laboratory for Agrobiotechnology, China Agricultural University, Beijing 100094, China, ${ }^{2}$ College of Life \\ Sciences, Sun Yat-Sen University, Guangzhou 510275, China, ${ }^{3}$ Marine Biological Laboratory, Woods Hole, \\ MA 02543, USA and ${ }^{4}$ Department of Molecular \& Integrative Physiology, University of Kansas Medical Center, \\ Kansas City, KS 66160, USA
}

Correspondence should be addressed to L Liu Email: liutelom@yahoo.com

\begin{abstract}
Cloning mammalians by somatic cell nuclear transfer (SCNT) remains inefficient. A majority of clones produced by SCNT fail to develop properly and of those which do survive, some exhibit early aging, premature death, tumors, and other pathologies associated with aneuploidy. Alterations of centrosomes are linked to aberrant cell cycle progression, aneuploidy, and tumorigenesis in many cell types. It remains to be determined how centrosomes are remodeled in cloned bovine embryos. We show that abnormalities in either distribution and/or number of centrosomes were evident in approximately $50 \%$ of reconstructed embryos following SCNT. Moreover, centrosome abnormalities and failed 'pronuclear' migration which manifested during the first cell cycle coincided with errors in spindle morphogenesis, chromosome alignment, and cytokinesis. By contrast, nuclear mitotic apparatus protein (NuMA) exhibited normal expression patterns at metaphase spindle poles and in 'pronucleus' during interphase. The defects in centrosome remodeling and 'pronuclear' migration could lead to chromosome instability and developmental failures associated with embryo production by SCNT. Addressing these fundamental problems may enhance production of normal clones.
\end{abstract}

Reproduction (2006) 131 1051-1061

\section{Introduction}

Cloning by somatic cell nuclear transfer (SCNT) has been successful in a variety of mammalian species yet remains quite inefficient. In addition to embryonic loss, SCNT is also associated with high rates of fetal, perinatal and neonatal wastage, as well as abnormal offspring (Renard et al. 1999, Wilmut et al. 2002). The fate of cloned embryos is determined by cellular and molecular events occurring within hours of nuclear transfer, but little is known about the nature and consequences of adaptations in the cell cycle that must take place during this critical period of development (Wilmut et al. 2002). Research on epigenetic reprogramming of somatic cell nuclei following nuclear transfer shows that aberrant molecular mechanisms may contribute to the inefficiency of cloning (Kang et al. 2001, Jaenisch et al. 2002, Xue et al. 2002, Yanagimachi 2002, Mann et al. 2003).

Yet little is known about the nuclear and cytoplasmic changes associated with the integration of donor cell components into the cytoplasm of the recipient ooplasm. Studies on SCNT embryos in the rhesus monkey have suggested that nuclear mitotic apparatus protein (NuMA) fails to reorganize during cell cycle progression (Simerly et al. 2003). Also, somatic donor cell centrosomes introduced during SCNT in the mouse appear to be rapidly degraded in activated ooplasts (Zhong et al. 2005). However, degradation of centrosomes was not seen in mouse cloning by Van Thuan et al. (2006).

Although the efficiency in cloning cattle has been relatively high, and some bovine clones appear healthy, both physically and behaviorally (Lanza et al. 2001), many others exhibit high rates of abortion, prenatal and newborn death (Tsunoda \& Kato 2002). Some clones of animals with shorter life-spans, such as mouse and sheep, develop chronic diseases, including obesity and diabetes, precocious aging, premature death, and tumors (KuhholzerCabot \& Brem 2002, Ogonuki etal. 2002, Gou etal.2003). It remains to be determined why some species are more easily cloned, and produce healthier offspring than others, 
or what mechanisms underlie the defective development of cloned embryos. Depletion of NuMA during enucleation of oocytes with removal of spindles may limit the efficiency of cloning some species, particularly primates (Simerly et al. 2003, 2004), resulting in aneuploidy. Chromosomal abnormalities are a well-known cause of subsequent developmental failure, pregnancy failure, embryonic loss during implantation, perinatal death, and congenital malformation (Ekins \& Shaver 1976, Hassold \& Hunt 2001, Racowsky 2002). Because in somatic cells, terminal phases of mitotic chromosome separation and/or nuclear reassembly require NuMA (Merdes \& Cleveland 1998) and functional centrosomes, it is imperative that the fate and function of centrosomes should be elucidated in SCNT embryos. In the present study, the spatial and temporal disposition of NuMA and centrosomes were studied in bovine SCNT embryos compared with parthenogenetic embryos and embryos produced by in vitro fertilization (IVF) using three-dimensional reconstruction during the first cell cycle.

\section{Materials and Methods}

\section{Fetal fibroblasts and adult granulosa cells}

Skin biopsy was obtained from a bovine fetus at day 80 of pregnancy, cut into small pieces, and cultured in DMEM (GIBCO) supplemented with $10 \%$ fetal bovine serum (FBS) at $37.5^{\circ} \mathrm{C}$ in $5 \% \mathrm{CO}_{2}$ and humidified air. After 3-6 days in culture, fibroblast cell monolayers formed around the tissue explants, which were then removed, and fibroblast cells were cultured to confluency. The cells were routinely passaged and maintained until passage 5-10. Bovine granulosa cells were collected by aspiration from ovarian follicles of 2-7 mm in diameter, washed by sedimentation and centrifugation twice, and cultured under the same condition as fetal fibroblasts. For each passage, cells were cultured until confluent, disaggregated by incubation in a $0.1 \%$ trypsin and EDTA solution for $1-2.5 \mathrm{~min}$ at $37^{\circ} \mathrm{C}$, and allocated to three new dishes for further passaging. For long-term storage, cells at different passages were collected following trypsin treatment and frozen stored in $10 \%$ dimethyl sulfoxide in liquid nitrogen.

\section{Recipient oocytes, IVF and embryo culture}

Procedures for in vitro maturation (IVM) and fertilization (IVF) of bovine oocytes were described previously (Liu et al. 1998, Dinnyes et al. 2000). Briefly, cumulusoocyte complexes (COCs) were aspirated from follicles (2-8 $\mathrm{mm}$ diameter) and selected based on their morphology. They were washed in maturation medium, which was comprised of tissue culture medium (TCM199; Life Technologies) supplemented with 10\% FBS, $0.01 \mathrm{U} / \mathrm{ml}$ bovine follicle-stimulating hormone $(\mathrm{bFSH})$, $0.01 \mathrm{U} / \mathrm{ml}$ bovine luteinizing hormone $(\mathrm{bLH}), 1 \mu \mathrm{g} / \mathrm{ml}$ estradiol-17 $\beta$ and $1 \%$ penicillin/streptomycin (Life Technologies). Approximately 50-60 COCs were transferred into $0.5 \mathrm{ml}$ maturation medium in 4-well dishes covered with mineral oil, and cultured at $38.5^{\circ} \mathrm{C}$ in $5 \%$ $\mathrm{CO}_{2}$ for 18-20 h.

Frozen-thawed sperm were washed twice by centrifugation in modified Brackett-Oliphant (m-BO) medium supplemented with $10 \mathrm{mM}$ caffeine and $4 \mathrm{mg} / \mathrm{ml} \mathrm{BSA}$, and then resuspended in the fertilization medium ( $\mathrm{m}-\mathrm{BO}$ medium supplemented with $10 \mu \mathrm{g} / \mathrm{ml}$ heparin and $4 \mathrm{mg} / \mathrm{ml} \mathrm{BSA}$ ). Sperm concentration was adjusted to $1 \times 10^{7} \mathrm{sperm} / \mathrm{ml}$, and approximately 25 oocytes were added to a $100 \mu \mathrm{l}$ fertilization-medium droplet. After $6 \mathrm{~h}$ co-incubation, oocytes were washed and cultured in CR1aa medium (Sims \& First 1994), supplemented with $0.1 \% \mathrm{BSA}$, for $48 \mathrm{~h}$ at $39{ }^{\circ} \mathrm{C}$ in a humidified atmosphere of $5 \% \mathrm{CO}_{2}$. After $48 \mathrm{~h}$ in culture, IVF eggs were freed of cumulus cells by pipetting, and cleavage was examined.

\section{Somatic cell nuclear transfer}

Enucleation of oocytes was achieved by piercing the zona pellucida with a glass needle and gently pushing out the polar body and surrounding cytoplasm (Gong et al. 2004). Successful enucleation was confirmed by Hoechst 33342 staining of extruded karyoplasts. Donor cells were starved to enrich them at $\mathrm{G}_{0}$ phase (Wilmut et al. 1997), and cultured for 3-4 days in DMEM/F12 containing $0.5 \%$ FBS after confluence. Prior to SCNT, cells were typsinized, centrifuged, and re-suspended with PBS supplemented with $0.5 \%$ FBS. Donor cells were then individually transferred into contact with enucleated recipient oocytes. Donor cell-cytoplasts were electrically fused in a chamber filled with Zimmerman cell fusion medium, induced with two DC pulses of $2.5 \mathrm{kV} / \mathrm{cm}$ for $10 \mu \mathrm{s}$ each at $1 \mathrm{~s}$ apart, delivered by a BTX2001 Electro Cell Manipulator (BTX, San Diego, CA, USA). Activation was induced by incubation in $10 \mu \mathrm{g} / \mathrm{ml}$ cycloheximide and $2.5 \mu \mathrm{g} / \mathrm{ml}$ cytochalasin D (Liu et al. 1998). Following activation, reconstructed embryos were cultured in CR1aa medium supplemented with $0.1 \%$ BSA as described above.

\section{Immunofluorescence microscopy}

Oocytes or embryos were washed in PBS containing 0.1\% polyvinyl pyrrolidone (PBS-PVP), then fixed as described previously (Combelles \& Albertini 2001). Oocytes were incubated overnight at $4{ }^{\circ} \mathrm{C}$ with mouse anti-NuMA, or mouse anti- $\gamma$ tubulin $(1: 100)$, washed, then labeled with FITC-anti-mouse IgG. Centrosomes were routinely identified by immunocytochemistry using antibodies specific to $\gamma$ tubulin, a core component of the centrosome (Doxsey et al. 1994, Merdes \& Cleveland 1997, Combelles \& Albertini 2001, Wong \& Stearns 2003, 
Sluder \& Nordberg 2004). The antibody against $\gamma$ tubulin, appearing as a single dot of labeling, corresponds to one centrosome (Wong \& Stearns 2003). Some oocytes were also stained for spindles with rat anti- $\alpha$ tubulin (Yol 34) and cy3 anti-rat $\operatorname{lgG}(1: 100)$. Oocytes were washed and mounted in Vectashield medium (Vector Laboratories, Burlingame, CA, USA) containing $0.5 \mu \mathrm{g} / \mathrm{ml}$ DAPI $\left(4^{\prime}, 6-\right.$ diamino-2-phenylindole). Immunofluorescence was detected with a Zeiss Axioplan 2 imaging microscope, equipped with epifluorescence, AxioCam and AxioVision 3.0 software, or with a Zeiss LSM 510 Meta laser scanning confocal microscope. Three-dimensional images were reconstructed and projected from serial optical Z-sections captured by the confocal microscope with its software.

\section{Results}

\section{Remodeling of NuMA in parthenogenetic, IVF, and SCNT embryos}

NuMA was shown by immunostaining to be weakly expressed as broad bands at both spindle poles in MII oocytes (Fig. 1A). Fertilized eggs exhibited increased NuMA staining in both female and male pronuclei (Fig. 1B and C), and at spindle poles during the first mitosis (Fig. 1D). Parthenogenetically activated oocytes retained NuMA staining at poles throughout the anaphase-telophase II transition (Fig. 1E and F). Between 8 and 24 h post-activation, NuMA labeling was evident in pronuclei (Fig. 1G and $\mathrm{H}$ ), and finally was restricted to both spindle poles in the first mitosis (Fig. 1I).

The nuclei of donor granulosa cells contained immunodetectable NuMA (Fig. 2A) and the NuMA disappeared in condensing nuclei soon after fusion with recipient oocytes (Fig. 2B). Labeling was readily apparent in enlarging 'pronuclei' at 2 and $4 \mathrm{~h}$ after cell fusion (Fig. 2C-E), and dramatically increased in enlarged "pronuclei" at 8 (Fig. 2F) and $18 \mathrm{~h}$ post-fusion. These events were followed, 22-24 h after nuclear transfer (NT), by chromosome condensation (Fig. 2G), nuclear breakdown, and the formation of a mitotic spindle, with NuMA accumulation at the spindle poles (Fig. 2H). Also, following cleavage of reconstituted embryos (by $24 \mathrm{~h}$ ), NuMA was present in the nuclei of blastomeres (Fig. 3).

NuMA staining after SCNT with fibroblasts exhibited patterns similar to those of granulosa cells. However, pronuclei derived from fibroblasts developed more slowly and appeared to contain lower levels of NuMA, being smaller at identical time points when compared with granulosa cells. Quantification of NuMA in granulosa and fibroblast embryos using digital imaging further confirmed that the initial onset and extent of NuMA accumulation was greater in granulosa compared with fibroblast SCNT embryos (Fig. $2 \mathrm{I}$ and J). While the significance of differential NuMA accumulation remains unclear, our studies demonstrate that NuMA remodeling during the first cell cycle in bovine nuclear transfer embryos proceeds as in fertilized or parthenogenetic embryos. Further evidence suggesting that NuMA is not a key regulator of initial cell cycle events in cloned embryos includes NuMA retention in nuclei of embryos that are abnormally cleaved or display aberrant pronuclear position (Fig. 3B-E), and the spindle pole staining observed in activated oocytes with dispersed chromosomes (Fig. 3F).

\section{Remodeling of centrosomes in parthenogenetic, IVF, and SCNT embryos}

Since centrosomes are crucial for the formation of spindle poles, chromosome segregation and cytokinesis (Doxsey 2001), we reasoned that these might be likely targets for reprogramming, especially as related to the cleavage defects and high rates of aneuploidy so commonly observed in SCNT embryos (Slimane-Bureau \& King 2002, Bureau et al. 2003, Shi et al. 2004). Centrosomes were identified by immunostaining with an antibody to $\gamma$ tubulin, which is a well-characterized centrosomal component (Nigg 2002, Matsumoto \& Maller 2004, Sluder \& Nordberg 2004), but would not enable us to identify centrioles. The combination of $\gamma$ tubulin with $\alpha$-tubulin and DAPI staining also allowed us to relate centrosome disposition to their cell cycle state and nucleation status respectively. No focal staining with $\gamma$ tubulin was evident in MIl oocytes (Fig. 4A), nor during anaphase-telophase II following activation (Fig. 4B) through pronuclear stages (Fig. 4C). Moreover, activated oocytes organized barrelshaped spindles at mitosis (Fig. 4D), and completed anaphase (Fig. 4E) and cell division without discernible $\gamma$ tubulin foci (Fig. 4F). In contrast, embryos produced by IVF exhibited two centrosomes around each blastomere nucleus (Fig. 4G). Interestingly, we found that $46 \%$ of activated oocytes $(n=24)$ showed abnormal cleavage, which included both anucleate and binucleate blastomeres, indicating a loss of coordination between karyokinesis and cytokinesis.

Prior to fusion with cytoplasts, $75 \%$ of granulosa cells exhibited one $\gamma$ tubulin focus organizing the microtubule network, whereas no comparable foci were seen in oocyte cytoplasts. Within $1 \mathrm{~h}$ after fusion, all donor nuclei had one or two $\gamma$ tubulin foci (Fig. 5A). At 2 h, pronuclei appeared somewhat swollen and enlarged, and most had two $\gamma$ tubulin foci close to the pronuclei in which a single $\gamma$ tubulin focus appeared to nucleate microtubule asters (Fig. 5B). By 4-8 h, pronuclei became markedly expanded and contained two perinuclear centrosomes (Fig. 5C). By $18 \mathrm{~h}$, most enlarged pronuclei moved to the center of the reconstituted oocytes and retained two perinuclear centrosomes that were often diametrically opposed at the pronuclear surface (Fig. 5D). By 22-24 h, NT embryos at the first mitosis showed centrosomes localized to each spindle pole as chromosomes aligned at the equatorial region from metaphase (Fig. 5E) through 

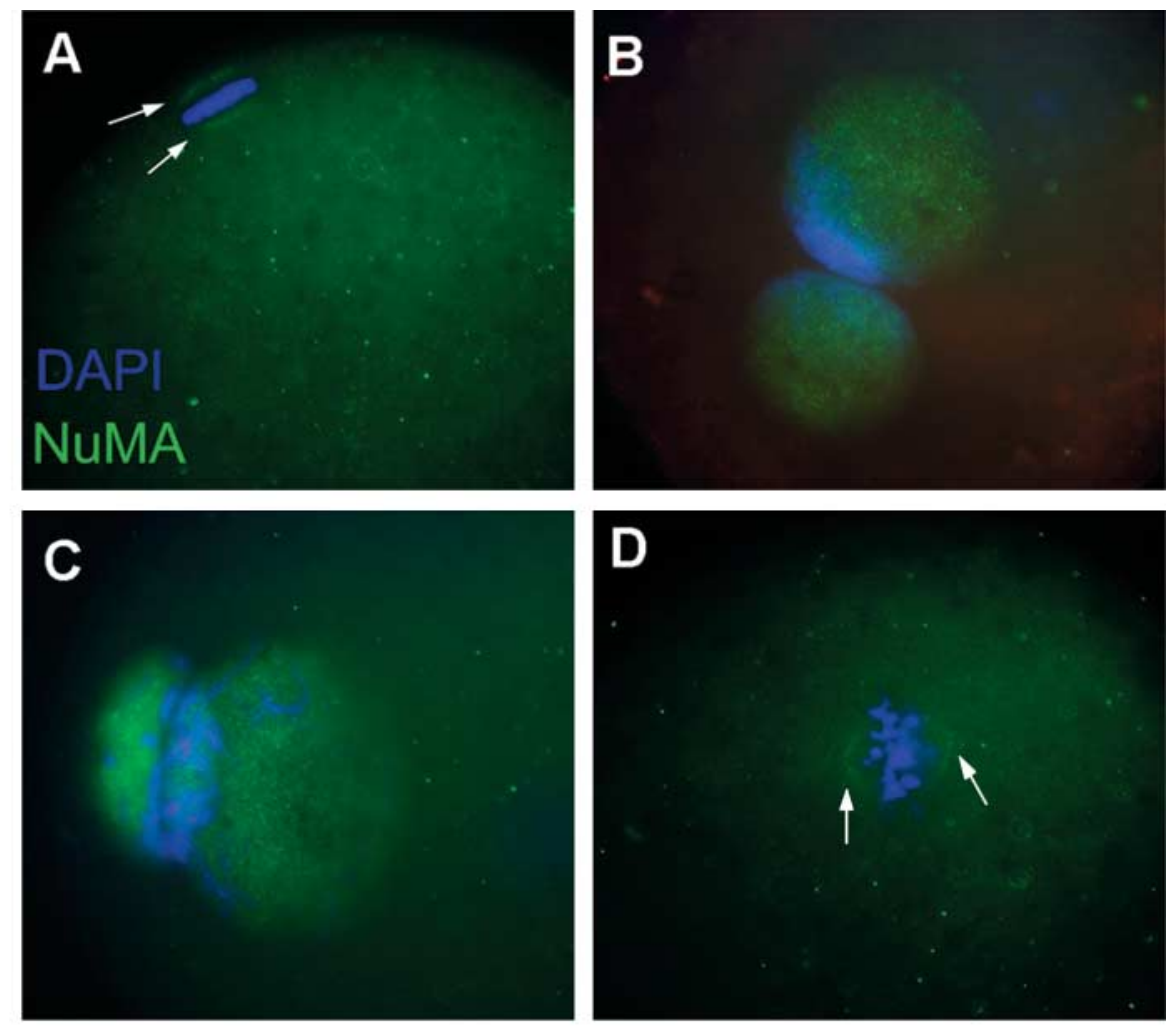

\section{DAPI+NuMA NuMA DAPI+ $\alpha$ tubulin}
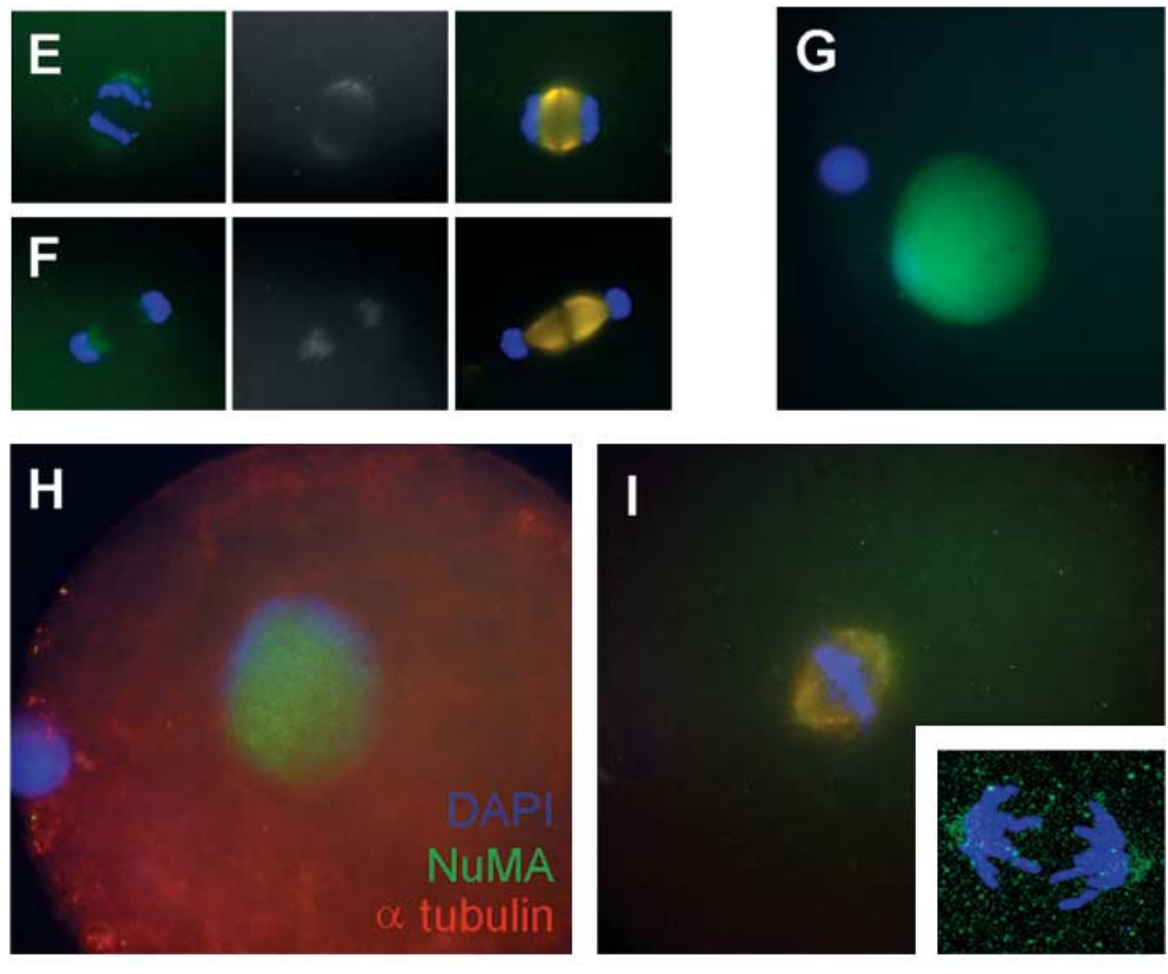

Figure 1 NuMA localization in bovine oocytes following in vitro fertilization (IVF) and parthenogenetic activation (PA). (A) MII oocytes. Arrow indicates NuMA. (B) NuMA accumulation in both female and male pronuclei $18 \mathrm{~h}$ after IVF. (C) NuMA associated with condensed chromosomes immediately following nuclear envelope breakdown $24 \mathrm{~h}$ after IVF. (D) Preferential accumulation of NuMA (arrows) at poles of the first mitosis. (E) Early anaphase II after PA. (F) Late anaphase II after PA. (G) NuMA accumulation in a female pronucleus $8 \mathrm{~h}$ after PA. (H) NuMA in a pronucleus $24 \mathrm{~h}$ after PA. (I) Preferential accumulation of NuMA at poles of PA embryos at mitotic and early anaphase (insert, $2 \times$ ). Scale bar, $25 \mu \mathrm{m}$. 

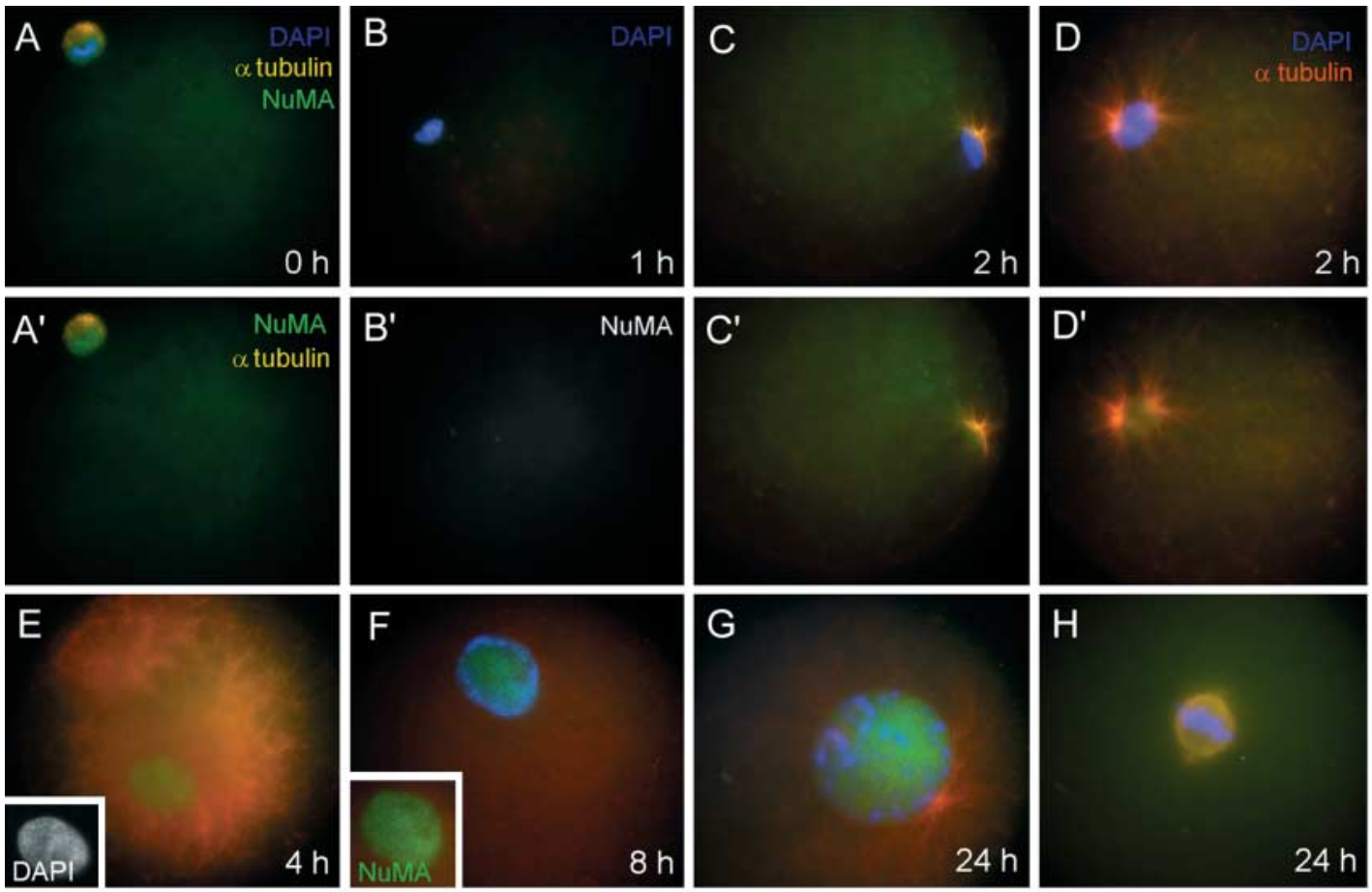

I

$\mathrm{J}$
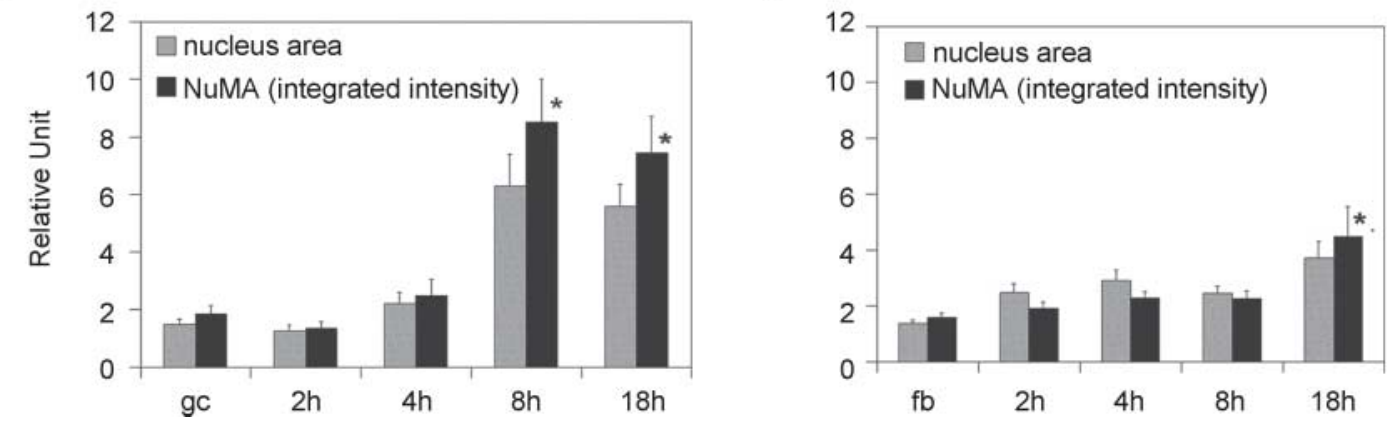

Figure 2 NuMA remodeling in nuclear transplant embryos from granulosa cells (gc) and fibroblasts (fb). (A) NuMA in nucleus of donor granulosa cell. (B) Absence of NuMA from condensed nucleus $1 \mathrm{~h}$ following nuclear transfer of granulosa cells. (C) NuMA starts to appear in the pronucleus at $2 \mathrm{~h}$, and one microtubule aster forms. (D) NuMA accumulation with formation of two microtubule asters. (E) Pronuclear swelling and NuMA

accumulation at 4 h. (F) Extensive NuMA accumulation at 8 h. (G) Nuclear envelope breakdown and NuMA surrounding the condensed chromatin at 24 h. (H) NuMA localization at poles of the first mitotic spindles. (I) Relative quantity of NuMA in nuclear transfer embryos from granulosa cells. (J) Relative quantity of NuMA in nuclear transfer embryos from fibroblasts. Scale bar, $25 \mu \mathrm{m}$.

anaphase (Fig. 5F). Most two-cell NT embryos contained perinuclear centrosomes (Fig. 5G). It is interesting to note that although a solitary centrosome was evident at the spindle pole at metaphase, two centrosomes, presumably produced through splitting, were apparent soon after initiation of anaphase and telophase (Fig. 5F). This pattern persisted in cleaved, two-cell embryos, and was not unlike what was observed in fertilized embryos at a similar stage of development (Fig. 4G).

Abnormalities in the number and distribution of centrosomes (compared with Fig. 5A-G), however, were apparent in a high percentage $(47 \%, n=45)$ of NT embryos produced with granulosa cells. The abnormalities fell into several categories that included (a) multiple centrosome foci that are either dissociated from the pronucleus (Fig. $5 \mathrm{H}$ and $\mathrm{I}$ ), or retain a perinuclear location (Fig. 5J), (b) spindle associated variants with three centrosomes associated with dispersed chromosomes (Fig. 5K) or a solitary ectopic centrosome near a misaligned chromosome when two other centrosomes are apparent at the poles of the metaphase spindle (Fig. 5L), and (c) variants in centrosome number such as solitary centrosomes in monopolar spindles with scattered chromosomes (Fig. 5M) or three centrosome foci surrounding the pronucleus (Fig. $5 \mathrm{~N}$ ). We often noticed that embryos 


\section{A $24 \mathrm{~h}$}
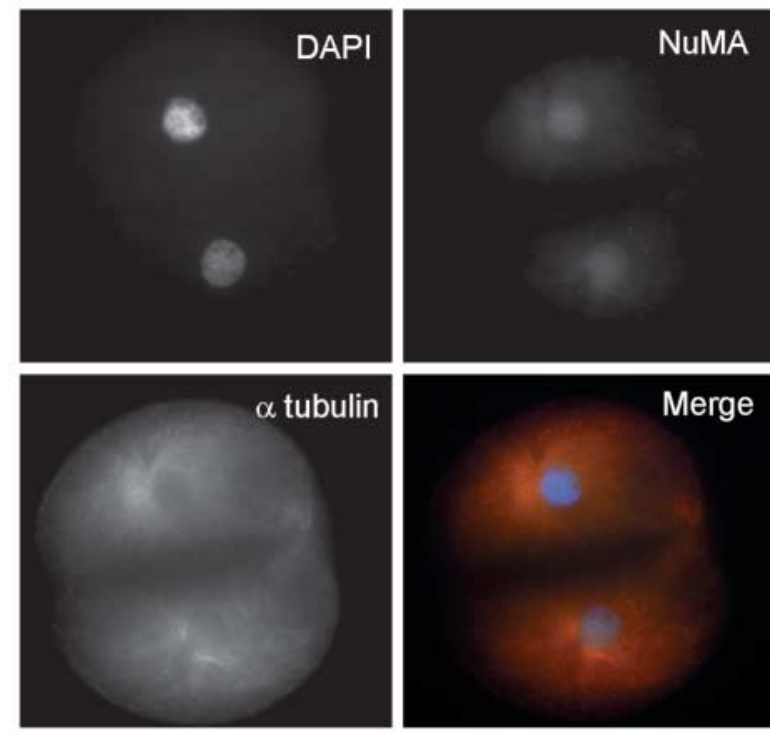

B $18 \mathrm{~h}$
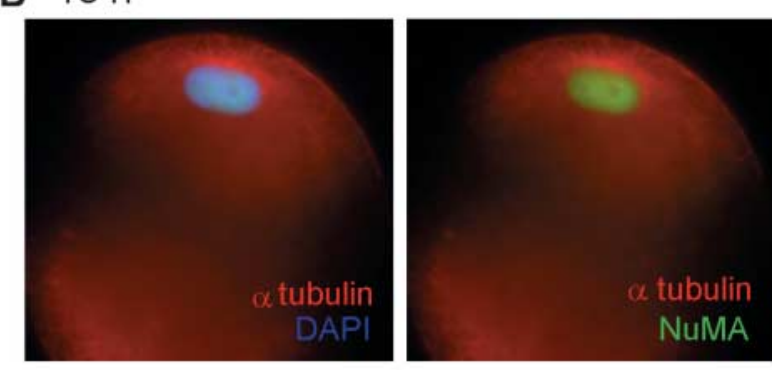

\section{C $18 \mathrm{~h}$}

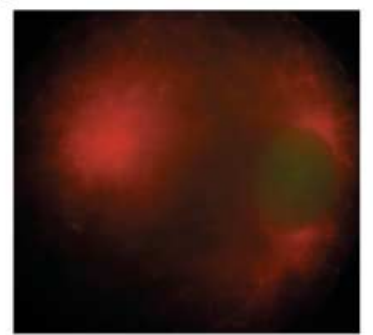

E $24 \mathrm{~h}$
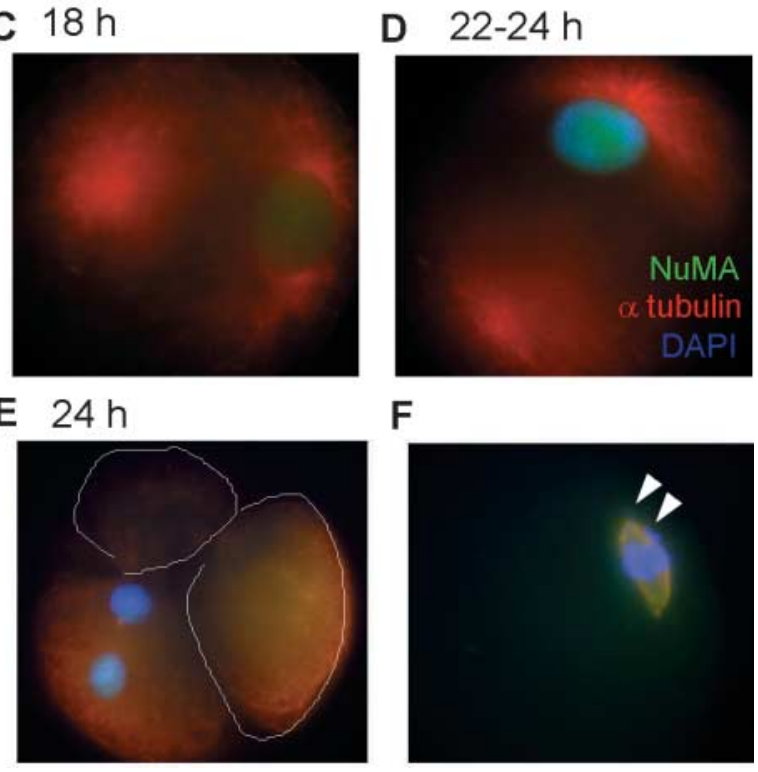

$\mathrm{F}$

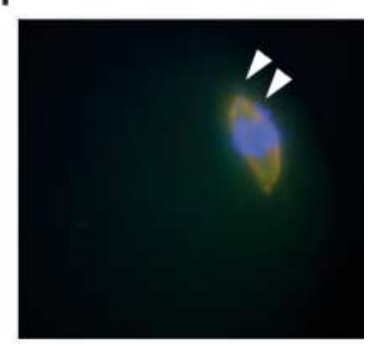

Figure 3 Localization of NuMA in cleaved, cloned embryos derived from granulosa cells. (A) NuMA in nucleus of normally cleaved, 2-cell embryos at $24 \mathrm{~h}$. (B, C) Abnormal cortical localization of nucleus and NuMA at 18 h. (D, E) Abnormal division 22-24 h after reconstitution. (F) Chromosome scattering (Arrowheads) on the spindle with NuMA at the poles.

with cortical pronuclei typically had a solitary perinuclear $\gamma$ tubulin focus and a second focus distant from the pronucleus. Moreover, abnormally cleaved 3-4 cell embryos either lacked centrosomes in one or more nuclei, or in some cases, centrosomes were present in one anucleate blastomere (Fig. 5O).

Variations in centrosome number (1-6 $\gamma$ tubulin foci) and localization (perinuclear or not) were also found at various stages of development in NT embryos derived from fibroblasts (data not shown). Briefly, like their granulosa cell counterparts, oocytes fused with donor fibroblasts developed microtubule asters radiating from one or two $\gamma$ tubulin foci, and at later time points (2-18 h) centrosomes remain perinulcear. Again, the first mitotic $M$ phase was characterized by abnormalities in chromosome alignment, multipolar spindles, and ectopic centrosomes. Thus, both donor cell types contribute centrosomes that are modified soon after fusion, and in roughly $50 \%$ of SCNT embryos, the integration of these structures into passage through the first cell cycle results in abnormalities that compromise early development.

\section{Discussion}

\section{Aberrant constitution of centrosomes is associated with formation of abnormal spindles and chromosome misalignments}

SCNT introduces centrosomes from donor somatic cells into oocyte cytoplasm, mimicking the introduction of centrosomes by sperm during fertilization (Navara et al. 1994, Shin et al. 2002). We also established that centrosomes in cloned cattle are unlikely to be provided by recipient cytoplasts of maternal origin. Furthermore, we found that the number of centrosomes varied from 2 to 6 in cloned embryos during first mitosis. Also, the centrosomes do not always associate with the pronucleus or perinuclear region; rather some are located away from nucleus.

Variable numbers of centrosomes could result from a duplication of centrosomes, driven by cytoplasmic conditions specific to cell cycle stages (Hinchcliffe \& Sluder 2001). Centrosome duplication occurs at G1/S phase, but not at G0 phase. This might explain the original success of somatic cell cloning using synchronization at G0. The centrosome duplicates once in S phase, which is controlled by a centrosome-intrinsic block to reduplication. However, G2 centrosomes are unable to reduplicate in a cellular environment that supports centrosome duplication (Wong \& Stearns 2003). In somatic cell nuclear transfer, S phase nuclei may undergo $\mathrm{S}$ phase reduplication of centrosomes following oocyte activation, thus resulting in variable numbers of centrosomes. The transferred centrosomes at G2 stage may not be able to duplicate in the subsequent ' $\mathrm{S}$ ' phase of activated oocyte cytoplasm. Thus, the cell cycle of donor cells influences reproduction of centrosomes following nuclear transfer. However, centrosome 

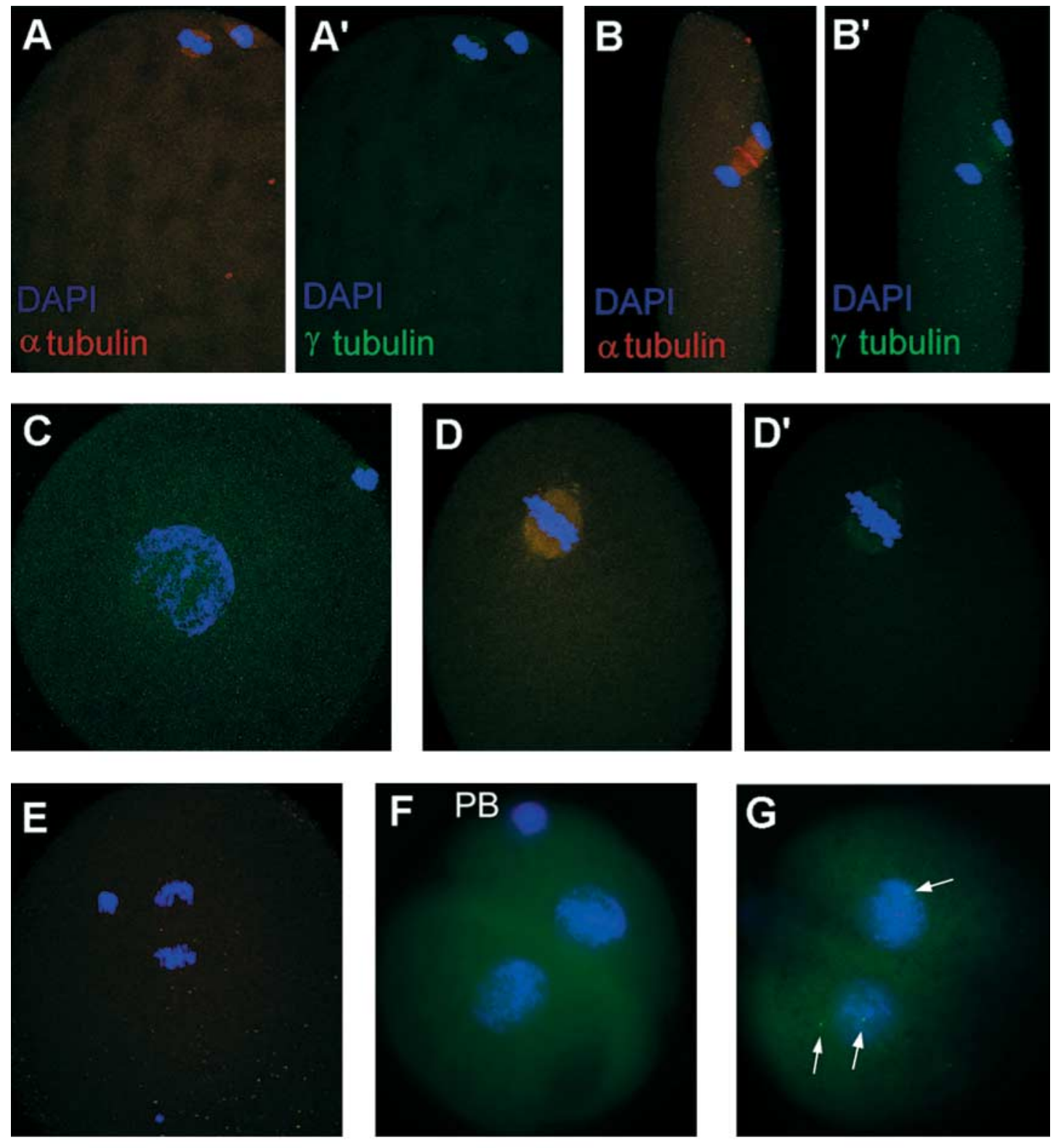

Figure 4 Centrosomal distribution in bovine oocytes following parthenogenetic activation (PA) or IVF. (A-F) MII and (PA) oocytes exhibit no centrosomal foci, but (G) IVF oocytes do. (A, $\left.\mathrm{A}^{\prime}\right)$ Absence of centrosome foci in MII oocytes. (B, $\left.\mathrm{B}^{\prime}\right)$ Oocytes $2 \mathrm{~h}$ after PA. (C) Pronuclei at $18 \mathrm{~h}$, and absence of centrosomal foci. (D, $\left.\mathrm{D}^{\prime}\right)$ The first mitosis of PA embryos at $24 \mathrm{~h}$ (D) Merged image of microtubule spindle and chromosomes stained by DAPI; ( $\left.D^{\prime}\right)$ Merged image of $\gamma$ tubulin staining, and chromosomes stained by DAPI. (E) Anaphase of PA embryos. (F) Cleaved 2-cell PA embryos; PB, polar body. (G) Cleaved 2-cell IVF embryos, showing two centrosomal foci (arrows) surrounding nuclei, a third is out of focus. (A-E) Threedimensional reconstruction using Z-serial section imaged with confocal microscopy. $(F, G)$ Conventional fluorescence images. Scale bar, $25 \mu \mathrm{m}$.

duplication does not require de novo protein synthesis, since an inhibitor of protein synthesis, cycloheximide, was present during the first $6 \mathrm{~h}$ following nuclear transfer, consistent with previous findings in embryos from other species (Gard et al. 1990, Sluder et al. 1990). The subunits for complete centrosome assembly can be stockpiled ahead of time, and the properly controlled use of these subunits for centrosome reproduction does not require nuclear transcription or nuclear DNA synthesis at each cell cycle (Sluder et al. 1986).

The origin of centrosomes differs among species. In most mammalian species, including primates and bovine, with the exception of mice and other rodents, the sperm contributes a centriole during fertilization and helps organize the assembly of the first mitotic spindle in the zygote (Schatten et al. 1985, 1986, Sutovsky \& Schatten 2000). Parthenogenetically activated 

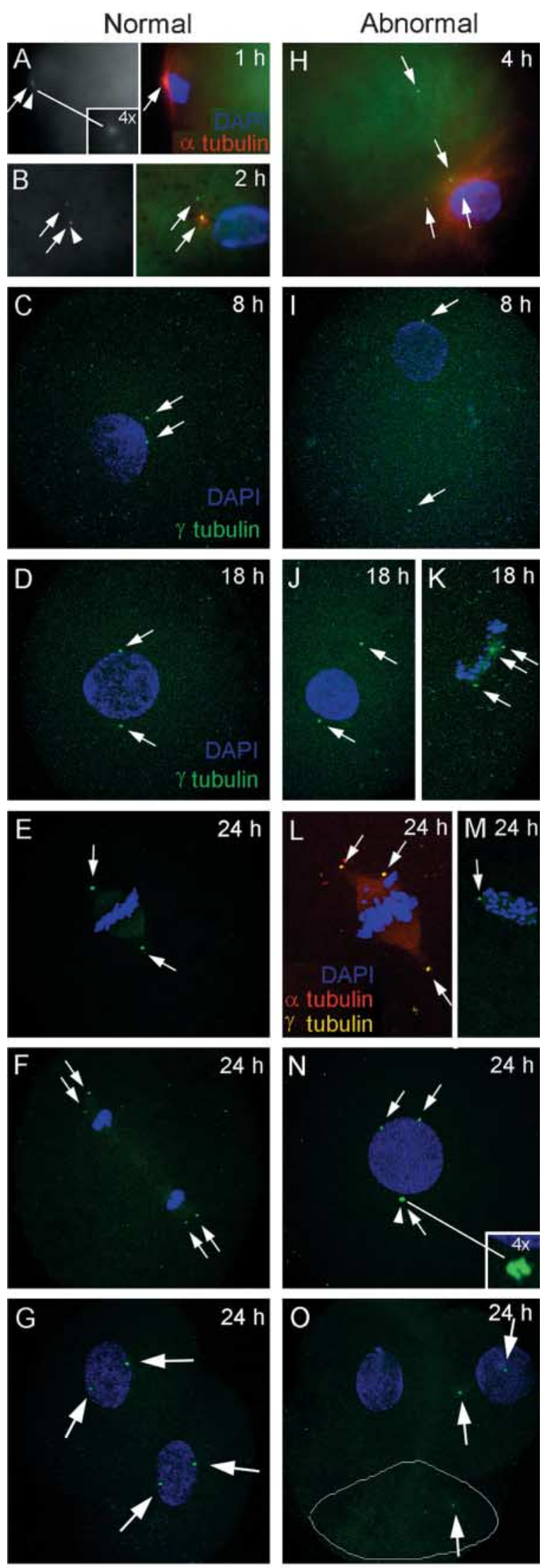

mouse eggs can assemble functional mitotic spindles and undergo mitosis without participation of sperm derived centrioles and centrosomes (Schatten et al. 1991). Bovine embryos appear to be an appropriate model to study centriolar inheritance (Sathananthan et al. 1997). In the absence of a paternally supplied centrosome, bovine oocytes can still be activated, and develop parthenogenetically to blastocysts with normal ploidy, at rates comparable to IVF derived embryos (Liu et al. 1998, Van De Velde et al. 1999), demonstrating that early embryos can develop without centrosomes. However, postimplantation development is severely compromised. Shin and Kim (2003) showed that $\gamma$-tubulin foci started to form in 8-16-cell stage bovine parthenotes (Shin \& Kim 2003). Centrosomes may enhance the fidelity of chromosome segregation.

Regardless of the origin of centrosomes, centrosome amplification can have serious consequences on subsequent development of clones. Indeed, chromosomal aberrations and aneuploidy are frequently found in cloned preimplantation embryos in cattle, rabbits and monkey (Slimane-Bureau \& King 2002, Vogel 2003, Shi et al. 2004) and in some embryos, aneuploidy seems not to be derived from the donor cells (Booth et al. 2003). Chromosomal abnormalities are also wellknown causes of developmental failure, perinatal death, and congenital malformations. The most frequently observed deviation from diploid karyotype was mixoploidy, resulting from aberrant cell division and polyploidy (Slimane-Bureau \& King 2002). At the first mitosis, centrosomes migrate to each spindle pole, and normal metaphase chromosome alignment ensues. Lack of centrosomes at one or both spindle poles, or abnormal numbers of centrosomes, promote chromo-

Figure 5 Centrosomal remodeling following nuclear transfer of granulosa cells. Shown are stages of normal (A-G) and abnormal $(\mathrm{H}-\mathrm{O})$ cell cycle progressions. (A) Centrosome (arrow) transferred with the nucleus of a donor cell $1 \mathrm{~h}$ after fusion. One aster is detected. Arrowhead indicates two closely associated $\gamma$ tubulin foci. (B) Two $\gamma$ tubulin foci surround the nucleus $2 \mathrm{~h}$ after fusion. (C) Two $\gamma$ tubulin foci surround the swollen pronucleus at $8 \mathrm{~h}$. (D) Two $\gamma$ tubulin foci move to opposite poles of the swollen pronucleus at $18 \mathrm{~h}$. (E) One $\gamma$ tubulin focus (arrow) at each pole of mitotic spindle at 22-24h. (F) Two $\gamma$ tubulin foci (arrows) appeared at anaphase-telophase transition.

(G) Two centrosomes surround nucleus of normally cleaved 2-cell NT embryos. (H) Four $\gamma$ tubulin foci near the nucleus, or distant from the pronucleus $4 \mathrm{~h}$ following fusion. (I) One $\gamma$ tubulin focus located distant from pronucleus. (J) One $\gamma$ tubulin focus remains dissociated from pronucleus. (K) Abnormal chromosome scattering with 3 disorganized $\gamma$ tubulin foci. (L) $\gamma$ tubulin foci at the poles, and also one associated with misaligned chromosomes at first mitosis. (M) One $\gamma$ tubulin focus associated with scattered chromosomes at one pole. $(\mathrm{N})$ Three $\gamma$ tubulin foci near a swollen pronucleus. (O) Abnormal distribution of centrosomes in abnormally cleaved 3-4-cell embryos at $24 \mathrm{~h}$. White circle indicates a blastomere without a nucleus. Blue, DNA stained with DAPI; green, $\gamma$ tubulin; red, $\alpha$ tubulin. (C-O) Three-dimensional reconstruction after Z-series section imaged by confocal microscopy. Scale bar, $25 \mu \mathrm{m}$. 
some misalignment or scattering at metaphase in cloned embryos, demonstrating that centrosomes are critical for normal chromosome segregation and ploidy in clones. Normal constitution and distribution of centrosomes are required to ensure the fidelity of chromosome segregation, and to maintain genomic stability during prenatal and postnatal development. Defects in centrosome remodeling likely lead to subsequent abortion of some clones, although it has not been determined whether these defects lead to chromosome instability and tumorigenesis in other clones.

\section{Abnormal distribution of centrosomes coincides with abnormal cleavage}

Normally, cleaved embryos divide equally, with centrosomes surrounding nuclei. Abnormal, unequally cleaved 3-4 cell embryos lacked nuclei in one or two blastomeres, some blastomeres had centrosomes and others did not. Our data demonstrate that abnormal cleavage coincides with aberrant distribution and numbers of centrosomes that may lead to a failure of pronuclei to move to the center in $35 \%$ of NT embryos. The centrosome has been known to direct the assembly of bipolar mitotic spindles, and thus determines the location of the cleavage furrow (Stevenson et al. 2001).

The formation of a functional mitotic spindle requires coordination between centrosomes and chromosomes (Zhang \& Nicklas 1995). Spindles assembled without centrosomes are anastral. However, if centrosomes are present, they become the primary organizer of spindles (de Saint Phalle \& Sullivan 1998). Animal cells that normally contain centrosomes can utilize a centrosome-independent pathway to form bipolar spindles (Khodjakov et al. 2000, Budde \& Heald 2003), but a complete lack of centrosomes impairs cytokinesis (Hinchcliffe et al. 2001). Thus, in the absence of centrosomes, bovine parthenotes proceed through the first mitosis but exhibit cleavage abnormalities consistent with this deficiency. Centrosome pathways are thought to be the dominant process in determining spindle polarity (Hinchcliffe \& Sluder 2001). Recent evidence suggests that the primary role of the centrosome in somatic cells may not be to form spindles, but rather to ensure cytokinesis and subsequent cell cycle progression (Khodjakov \& Rieder 2001). Through astral microtubules, centrosomes determine spindle polarity, spindle position/orientation and cleavage plane. When mammalian somatic cells enter mitosis with extra centrosomes, they are apt to assemble multipolar spindles and divide into more than two daughter cells (Sluder et al. 1997). Abnormal localization of centrosomes, therefore, would be expected to lead to abnormal cleavage or fragmentation of NT embryos at first mitosis.

\section{Functions of NuMA in reprogramming and cell replication}

The formation of mitotic centrosomes is a complex process in which a number of cellular proteins translocate to mitotic poles and play critical roles in the organization of the mitotic apparatus. The abundant coiled-coil protein NuMA is located in the nucleus during interphase, but when the nuclear envelope disassembles in prometaphase it rapidly redistributes to the developing spindle poles, and becomes transiently associated with centrosomes, and is involved at the spindle poles in mitosis and chromosome segregation (Cleveland 1995, Taimen et al. 2000, Du et al. 2001).

We observed nuclear organization of NuMA in bovine oocytes during the cell cycle following nuclear transfer of two types of cells: granulosa cells and fetal fibroblasts. NuMA was also was detected in pronuclear stage embryos of mouse clones and in donor cumulus cells (Moreira et al. 2003), as well as in normal bovine embryos (Degrouard et al. 2004). In bovine clones produced by simultaneous fusion and activation, NuMA was weak or absent in donor nuclei, but strongly expressed in pronuclei following NT. Consistently, weak or absent staining for NuMA was found in the nuclei of granulosa cells and fibroblasts after several passages in serum-starved conditions, consistent with reports by Taimen et al. (2000). Oocyte cytoplasm reactivates expression of NuMA in the 'pronucleus'. This dramatic redistribution of NuMA can be critical for nuclear remodeling and molecular events for initial development. These findings differ from those of most monkey clone embryos during the first mitosis, which exhibit depletion of NuMA (Simerly et al. 2003), indicative of both lack of nuclear reprogramming and defects in spindle polar function.

In bovine clones, NuMA may result from de novo synthesis, since transplanted nuclei lack NuMA staining for a few hours until expanded pronuclei have formed following NT. Cycloheximide also was used as a protein synthesis inhibitor in the present bovine cloning procedure, which may contribute to lack of NuMA in the introduced nuclei for a few hours. After removal of cycloheximide $6 \mathrm{~h}$ following NT, extensive translation and expression of NuMA could occur. Consistently, NuMA reassembles as a result of translation from maternal mRNA and of de novo transcription from transplanted nuclear genomes in the mouse cloning (Moreira et al. 2003). NuMA could be important for spindle pole organization in primates (Simerly et al. 2003). Without these proteins, resulting cells become aneuploid. In bovine clones, NuMA was detected at both poles of normal spindles with chromosome alignment at the metaphase plates as well as at poles of abnormally 
elongated or disrupted spindles with misaligned chromosomes, indicating that NuMA was not necessarily a key player in organization of mitotic spindle poles in this species. Yet, increased centrosomes were found to coincide with multipolar spindle formation, whereas lack of $\gamma$ tubulin or centrosome duplication prior to mitosis can lead to monopolar spindle formation and chromosome scattering, demonstrating that centrosomes are critical for maintaining functional mitosis in clones.

NuMA in bovine oocytes was distributed in both cytoplasm and to some extent on the poles of meiotic spindles. The presence of NuMA in cytoplasm after enucleation, possibly de novo synthesis of NuMA, or relocalization of NuMA from cytoplasm to the nuclei following nuclear transfer and oocyte activation might contribute to the greater success of bovine cloning and other species. Aberrant centrosome replication could be a major cause of abnormal cleavage of early embryos. It remains to be determined how somatic cell nuclei in NT and sperm in fertilization initiate $\gamma$ tubulin formation in the oocyte cytoplasm. We speculate that cloning efficiency by SCNT will be greatly improved in most species by assuring normal centrosome remodeling.

\section{Acknowledgements}

We thank D Compton for providing antibody to NuMA, and J Kilmartin for $\alpha$ tubulin antibody. This study was supported by China National Nature Science Foundation (LL), Project "973", China Ministry of Science and Technology (YD, NL), and Brown/Women \& Infants Faculty Research Fund (DK), the ESHE Fund (DFA) and the Hall Fund of Kansas University (DFA). The authors declare that there is no conflict of interest that would prejudice the impartiality of this scientific work.

\section{References}

Booth PJ, Viuff D, Tan S, Holm P, Greve T \& Callesen H 2003 Numerical chromosome errors in day 7 somatic nuclear transfer bovine blastocysts. Biology of Reproduction 68 922-928.

Budde PP \& Heald R 2003 Centrosomes and kinetochores, who needs 'em? The role of noncentromeric chromatin in spindle assembly. Current Topics in Developmental Biology 56 85-113.

Bureau WS, Bordignon V, Leveillee C, Smith LC \& King WA 2003 Assessment of chromosomal abnormalities in bovine nuclear transfer embryos and in their donor cells. Cloning Stem Cells 5 123-132.

Cleveland DW 1995 NuMA: a protein involved in nuclear structure, spindle assembly, and nuclear re-formation. Trends in Cell Biology 5 60-64.

Combelles CM \& Albertini DF 2001 Microtubule patterning during meiotic maturation in mouse oocytes is determined by cell cyclespecific sorting and redistribution of gamma-tubulin. Developmental Biology 239 281-294.

Degrouard J, Hozak P, Heyman Y \& Flechon JE 2004 Nucleoskeleton of early bovine embryos and differentiated somatic cells: an ultrastructural and immunocytochemical comparison. Histochemistry and Cell Biology 121 441-451.

Dinnyes A, Dai Y, Jiang S \& Yang X 2000 High developmental rates of vitrified bovine oocytes following parthenogenetic activation, in vitro fertilization, and somatic cell nuclear transfer. Biology of Reproduction 63 513-518.
Doxsey S 2001 Re-evaluating centrosome function. Nature Reviews Molecular Cell Biology 2 688-698.

Doxsey SJ, Stein P, Evans L, Calarco PD \& Kirschner M 1994 Pericentrin, a highly conserved centrosome protein involved in microtubule organization. Cell 76 639-650.

Du Q, Stukenberg PT \& Macara IG 2001 A mammalian partner of inscuteable binds NuMA and regulates mitotic spindle organization. Nature Cell Biology 3 1069-1075.

Ekins JG \& Shaver EL 1976 Cytogenetics of postimplantation rabbit conceptuses following delayed fertilization. Teratology 13 57-63.

Gard DL, Hafezi S, Zhang T \& Doxsey SJ 1990 Centrosome duplication continues in cycloheximide-treated Xenopus blastulae in the absence of a detectable cell cycle. Journal of Cell Biology $\mathbf{1 1 0}$ 2033-2042.

Gong G, Dai Y, Fan B, Zhu H, Zhu S, Wang H, Wang L, Tang B, Li R, Wan $\mathbf{R}$ et al. 2004 Birth of calves expressing the enhanced green fluorescent protein after transfer of fresh or vitrified/thawed blastocysts produced by somatic cell nuclear transfer. Molecular Reproduction and Development 69 278-288.

Gou KM, An XR, Guan H, Yang XY, Hou J, Zhu SE, Zeng SM, Tian JH \& Chen YF 2003 Transgenic twin lambs cloned by granulosa cells. Cloning Stem Cells 5 71-78.

Hassold T \& Hunt P 2001 To err (meiotically) is human: the genesis of human aneuploidy. Nature Reviews Genetics 2 280-291.

Hinchcliffe EH, Miller FJ, Cham M, Khodjakov A \& Sluder G 2001 Requirement of a centrosomal activity for cell cycle progression through G1 into S phase. Science 291 1547-1550.

Hinchcliffe EH \& Sluder G 2001 "It takes two to tango": understanding how centrosome duplication is regulated throughout the cell cycle. Genes \& Development 15 1167-1181.

Jaenisch R, Eggan K, Humpherys D, Rideout W \& Hochedlinger K 2002 Nuclear cloning, stem cells, and genomic reprogramming. Cloning Stem Cells 4 389-396.

Kang YK, Koo DB, Park JS, Choi YH, Chung AS, Lee KK \& Han YM 2001 Aberrant methylation of donor genome in cloned bovine embryos. Nature Genetics 28 173-177.

Khodjakov A, Cole RW, Oakley BR \& Rieder CL 2000 Centrosomeindependent mitotic spindle formation in vertebrates. Current Biology 10 59-67.

Khodjakov A \& Rieder CL 2001 Centrosomes enhance the fidelity of cytokinesis in vertebrates and are required for cell cycle progression. Journal of Cell Biology 153 237-242.

Kuhholzer-Cabot B \& Brem G 2002 Aging of animals produced by somatic cell nuclear transfer. Experimental Gerontology 37 1317-1323.

Lanza RP, Cibelli JB, Faber D, Sweeney RW, Henderson B, Nevala W, West MD \& Wettstein PJ 2001 Cloned cattle can be healthy and normal. Science 294 1893-1894.

Liu L, Ju JC \& Yang X 1998 Parthenogenetic development and protein patterns of newly matured bovine oocytes after chemical activation. Molecular Reproduction and Development 49 298-307.

Mann MR, Chung YG, Nolen LD, Verona RI, Latham KE \& Bartolomei MS 2003 Disruption of imprinted gene methylation and expression in cloned preimplantation stage mouse embryos. Biology of Reproduction 69 902-914.

Matsumoto Y \& Maller JL 2004 A centrosomal localization signal in cyclin E required for Cdk2-independent S phase entry. Science 306 885-888.

Merdes A \& Cleveland DW 1997 Pathways of spindle pole formation: different mechanisms; conserved components. Journal of Cell Biology 138 953-956.

Merdes A \& Cleveland DW 1998 The role of NuMA in the interphase nucleus. Journal of Cell Science 111 (Pt 1) 71-79.

Moreira PN, Robl JM \& Collas P 2003 Architectural defects in pronuclei of mouse nuclear transplant embryos. Journal of Cell Science 116 3713-3720.

Navara CS, First NL \& Schatten G 1994 Microtubule organization in the cow during fertilization, polyspermy, parthenogenesis, and nuclear transfer: the role of the sperm aster. Developmental Biology 162 29-40. 
Nigg EA 2002 Centrosome aberrations: cause or consequence of cancer progression? Nature Reviews Cancer 2 815-825.

Ogonuki N, Inoue K, Yamamoto Y, Noguchi Y, Tanemura K, Suzuki O, Nakayama H, Doi K, Ohtomo Y, Satoh M et al. 2002 Early death of mice cloned from somatic cells. Nature Genetics 30 253-254.

Racowsky C 2002 High rates of embryonic loss, yet high incidence of multiple births in human ART: is this paradoxical? Theriogenology 57 87-96.

Renard JP, Chastant S, Chesne P, Richard C, Marchal J, Cordonnier N, Chavatte P \& Vignon X 1999 Lymphoid hypoplasia and somatic cloning. Lancet 353 1489-1491.

de Saint Phalle B \& Sullivan W 1998 Spindle assembly and mitosis without centrosomes in parthenogenetic Sciara embryos. Jouranl of Cell Biology 141 1383-1391.

Sathananthan AH, Tatham B, Dharmawardena V, Grills B, Lewis I \& Trounson A 1997 Inheritance of sperm centrioles and centrosomes in bovine embryos. Archives of Andrology 38 37-48.

Schatten G, Simerly C \& Schatten H 1985 Microtubule configurations during fertilization, mitosis, and early development in the mouse and the requirement for egg microtubule-mediated motility during mammalian fertilization. PNAS 82 4152-4156.

Schatten G, Simerly C \& Schatten H 1991 Maternal inheritance of centrosomes in mammals? Studies on parthenogenesis and polyspermy in mice. PNAS $\mathbf{8 8}$ 6785-6789.

Schatten H, Schatten G, Mazia D, Balczon R \& Simerly C 1986 Behavior of centrosomes during fertilization and cell division in mouse oocytes and in sea urchin eggs. PNAS 83 105-109.

Shin MR \& Kim NH 2003 Maternal gamma (gamma)-tubulin is involved in microtubule reorganization during bovine fertilization and parthenogenesis. Molecular Reproduction and Development 64 438-445.

Shin MR, Park SW, Shim H \& Kim NH 2002 Nuclear and microtubule reorganization in nuclear-transferred bovine embryos. Molecular Reproduction and Development 62 74-82.

Shi W, Dirim F, Wolf E, Zakhartchenko V \& Haaf T 2004 Methylation reprogramming and chromosomal aneuploidy in in vivo fertilized and cloned rabbit preimplantation embryos. Biology of Reproduction 71 340-347.

Simerly C, Dominko T, Navara C, Payne C, Capuano S, Gosman G, Chong KY, Takahashi D, Chace C, Compton D et al. 2003 Molecular correlates of primate nuclear transfer failures. Science $\mathbf{3 0 0} 297$.

Simerly C, Navara C, Hwan Hyun S, Chun Lee B, Keun Kang S, Capuano S, Gosman G, Dominko T, Chong KY, Compton D et al. 2004 Embryogenesis and blastocyst development after somatic cell nuclear transfer in nonhuman primates: overcoming defects caused by meiotic spindle extraction. Developmental Biology 276 237-252.

Sims M \& First NL 1994 Production of calves by transfer of nuclei from cultured inner cell mass cells. PNAS 91 6143-6147.

Slimane-Bureau WC \& King WA 2002 Chromosomal abnormalities: a potential quality issue for cloned cattle embryos. Cloning Stem Cells 4 319-329.

Sluder G, Miller FJ, Cole R \& Rieder CL 1990 Protein synthesis and the cell cycle: centrosome reproduction in sea urchin eggs is not under translational control. Journal of Cell Biology $1102025-2032$.

Sluder G, Miller FJ \& Rieder CL 1986 The reproduction of centrosomes: nuclear versus cytoplasmic controls. Journal of Cell Biology 103 $1873-1881$

Sluder G \& Nordberg J 2004 The good, the bad and the ugly: the practical consequences of centrosome amplification. Current Opinion in Cell Biology 16 49-54.
Sluder G, Thompson EA, Miller FJ, Hayes J \& Rieder CL 1997 The checkpoint control for anaphase onset does not monitor excess numbers of spindle poles or bipolar spindle symmetry. Journal of Cell Science 110 ( $\mathrm{Pt}$ 4) 421-429.

Stevenson VA, Kramer J, Kuhn J \& Theurkauf WE 2001 Centrosomes and the Scrambled protein coordinate microtubule-independent actin reorganization. Nature Cell Biology 3 68-75.

Sutovsky P \& Schatten G 2000 Paternal contributions to the mammalian zygote: fertilization after sperm-egg fusion. International Review of Cytology 195 1-65.

Taimen P, Viljamaa M \& Kallajoki M 2000 Preferential expression of NuMA in the nuclei of proliferating cells. Experimental Cell Research 256 140-149.

Tsunoda Y \& Kato Y 2002 Recent progress and problems in animal cloning. Differentiation 69 158-161.

Van De Velde A, Liu L, Bols PE, Ysebaert MT \& Yang X 1999 Cell allocation and chromosomal complement of parthenogenetic and IVF bovine embryos. Molecular Reproduction and Development $\mathbf{5 4}$ $57-62$.

Van Thuan N, Wakayama S, Kishigami S \& Wakayama T 2006 Donor centrosome regulation of initial spindle formation in mouse somatic cell nuclear transfer: roles of gamma-tubulin and nuclear mitotic apparatus protein 1 Biology of Reproduction. $\mathbf{7 4}$ 777-787.

Vogel G 2003 Nuclear transfer. Misguided chromosomes foil primate cloning. Science 300 225-227.

Wilmut I, Beaujean N, de Sousa PA, Dinnyes A, King TJ, Paterson LA, Wells DN \& Young LE 2002 Somatic cell nuclear transfer. Nature 419 583-586.

Wilmut I, Schnieke AE, McWhir J, Kind AJ \& Campbell KH 1997 Viable offspring derived from fetal and adult mammalian cells. Nature 385 810-813.

Wong C \& Stearns T 2003 Centrosome number is controlled by a centrosome-intrinsic block to reduplication. Nature Cell Biology 5 539-544.

Xue F, Tian XC, Du F, Kubota C, Taneja M, Dinnyes A, Dai Y, Levine H, Pereira LV \& Yang X 2002 Aberrant patterns of $X$ chromosome inactivation in bovine clones. Nature Genetics $\mathbf{3 1}$ 216-220.

Yanagimachi R 2002 Cloning: experience from the mouse and other animals. Molecular and Cellular Endocrinology 187 241-248.

Zhang D \& Nicklas RB 1995 The impact of chromosomes and centrosomes on spindle assembly as observed in living cells. Journal of Cell Biology 129 1287-1300.

Zhong ZS, Zhang G, Meng XQ, Zhang YL, Chen DY, Schatten H \& Sun QY 2005 Function of donor cell centrosome in intraspecies and interspecies nuclear transfer embryos. Experimental Cell Research $30635-46$.

Received 30 November 2005

First decision 2 February 2006

Revised manuscript received 3 February 2006

Accepted 13 March 2006 